Contract No. and Disclaimer:

This manuscript has been authored by Savannah River Nuclear Solutions, LLC under Contract No. DE-AC09-08SR22470 with the U.S. Department of Energy. The United States Government retains and the publisher, by accepting this article for publication, acknowledges that the United States Government retains a non-exclusive, paid-up, irrevocable, worldwide license to publish or reproduce the published form of this work, or allow others to do so, for United States Government purposes. 


\title{
Characterization of Secondary Phases and Other Defects in CdZnTe
}

\author{
Martine C. Duff*, Savannah River National Laboratory, Aiken, SC 29808
}

Kelvin G. Lynn, Kelly Jones, Rajeswari Soundararajan, Washington State University, Pullman, WA 99164-2920

John P. Bradley, Hope Ishii, Jeffery Aguiar, Penny Wozniakiewicz, Lawrence Livermore National Laboratory, Livermore, CA 94550

*To whom correspondence should be addressed. E-mail: martine.duff@s,srnl.doe.gov

\begin{abstract}
Semiconducting CdZnTe or "CZT" crystals are very suitable for use as a room temperature-based gamma radiation spectrometer. During the last decade, modifications in growth methods for CZT have significantly improved the quality of the produced crystals however there are material features that can influence the performance of these materials as radiation detectors. For example, various structural heterogeneities within the CZT crystals, such as, pipes, voids, polycrystallinity, and secondary phases (SP) can have a negative impact on the detector performance. In this study, a CZT material was grown by the modified vertical Bridgman growth (MVB) method with zone leveled growth in the absence of excess Te in the melt. Numerous SP were imaged using transmission IR at a volume $\%$ of 0.002 . Samples from this material were analyzed using various analytical techniques to evaluate its electrical properties, purity and detector performance as radiation spectrometers and to determine the morphology, dimension and elemental /structural composition of one of the SP in this material. This material was found to have a high resistivity and good radiation spectrometer performance. It had SPs that were rich in calcium $(\mathrm{Ca})$, carbon $(\mathrm{C})$ and oxygen $(\mathrm{O})$ (possibly $\mathrm{CaCO}_{3}$ ) or only $\mathrm{C}$ and $\mathrm{O}$ that were $5 \mu \mathrm{m}$ or less in diameter.

KEYWORDS: Modified vertical Bridgman, transmission electron microscopy, carbon, calcite, transmission IR imaging
\end{abstract}

\section{INTRODUCTION}

CdZnTe (or CZT) crystals can be used in a variety of detector-type applications. Single crystal CZT has a large band gap and it shows great promise for use as a gamma radiation spectrometer. The performance of CZT is diminished by point defects, structural and compositional heterogeneities within the crystals, such as twinning, pipes, grain boundaries (polycrystallinity), various types of voids and SP..$^{1-7}$ However, as the size of useful detectors has increased from a few $\mathrm{mm}^{3}$ to a few $\mathrm{cm}^{3}$, the limiting factor in the detector performance has varied from electron and 
hole trapping by point defects, pipes and cracks to what been named in the literature (according to theory) as either Te inclusions or as Te precipitates. ${ }^{6-9}$ One explanation for formation of Te-rich SP is has been attributed to excess Te in the melt of CZT and CdTe phases. Even if the starting boule charge is stoichiometric or slightly Cd-rich, the most volatile element in the melt (i.e., Cd) will preferentially evaporate into the free space of the ampoule and leave behind a Te-rich melt. Such Te-rich phases may form during crystal growth or post growth annealing due to the retrograde solubility within the phase diagram. ${ }^{10-11}$ Twenty $\mu \mathrm{m}$-sized SP containing Te as well as $\mathrm{Cd}$ and $\mathrm{Zn}$ have been identified in Modified vertical Bridgmon (MVB) grown CZT. ${ }^{12}$ However, $90 \%$ of the SP in this one MVB grown material were also $20-\mu \mathrm{m}$ diameter voids with trace levels of CdZnTe residues. These voids and somewhat spherical Te, $\mathrm{Cd}$ and $\mathrm{Zn}$ rich SP were readily observed as being dark features in transmission IR imaging studies. Large voids have also been found in other MVB-grown material. ${ }^{9}$

Several modifications in the CZT growth methods have achieved considerable minimization of the dark features that are observed during transmission IR imaging of CZT. Those CZT crystals made using low pressure $\mathrm{MVB}^{13}$ and the traveling heater method or THM (by Redlen Technologies in Canada) ${ }^{14-15}$ growth processes have demonstrated good control of the growth. These methods can also produce large (seeded) single crystals. CZT syntheses have improved greatly during the last 15 years however the main performance limitation of CZT for use as a large volume radiation spectrometer is attributed SP. In our presentation, we will describe the characterization of a CZT material with good radiation detector performance with the use of computerized quantitative IR imaging, scanning and transmission electron microscopy, bulk resistivity measurements, electron mobility and elemental compositional analyses.

\section{EXPERIMENTAL}

A small CZT crystal with the dimension of $1.0 \times 1.0 \times 0.2 \mathrm{~cm}^{3}$ that we characterized in this study was grown at Washington State University using a zone leveled MVB growth method. ${ }^{14-17}$ In this method, Cadmium Zinc Telluride (CdZnTe with $10 \% \mathrm{Zn}$ ) is grown as a single crystal boule $47 \mathrm{~mm}$ in diameter and $118 \mathrm{~mm}$ long was produced. No Te excess was used in the melt and all metals used were $>6 \mathrm{~N}$ purity. The feed materials were doped with indium to compensate for electrical defects that are related to $\mathrm{Cd}$ loss during growth and were cooled down within 2 to 3 days. Grown boules were cut to appropriate thickness to provide a final detector thickness of roughly $2 \mathrm{~mm}$. Glow discharge mass spectrometric (GDMS) measurements were made on selected samples of material from the boule in areas near the sample detector material of interest. The techniques that were used included measurements of electronic properties 
through mu tau electron mobility, bulk resistivity and detector performance tests with a gamma radiation source. These measurements were made before and after anneal in oxygen $\left(\mathrm{O}_{2}\right)$ for $8 \mathrm{hrs}$ at $75^{\circ} \mathrm{C}$ with the exception of mu tau measurements, which were only performed on the annealed sample.

We also performed visible and transmission IR imaging. After polishing with alumina powders down to 0.3 $\mu \mathrm{m}$, these crystals were characterized by transmission IR imaging using a Sony CCD-IRIS camera for image recording. They were then prepared with gold $(\mathrm{Au})$ contacts deposited by sputtering in vacuum. The Au contacts permitted detector performance testing in a planar geometry using a ${ }^{57} \mathrm{Co}$ gamma source with a Tennelec amplifier. Currentvoltage (I-V) curves were obtained using the Keithley 237 Power Unit assisted by a PC computer using the ICS (Interactive Characterization Software) software of Metrics Technology Inc.

After the above characterization, the Au-sputtering was removed by polishing followed by ultrasonic cleaning. The cleaned material was sent to LLNL for examination by Scanning Electron Microscopy (SEM) using an FEI Nova 600 Nanolab Dualbeam Focussed Ion Beam Scanning Electron Microscope (FIB-SEM) at $5 \mathrm{keV}$ to analyze and produce a thin section of an SP-based area of interest through focused ion-beam milling for high resolutiontransmission electron microscopy (HR-TEM) studies. The HR-TEM studies were performed with a $200 \mathrm{keV}$ FEI Technai20 G2 FEG monochromated scanning transmission electron microscope (STEM) with high angle annular dark field (HAADF) detector using a $\mathrm{Si}(\mathrm{Li})$ solid state X-ray detector with 0.3 steradians solid angle.

\section{RESULTS AND DISCUSSION}

Optical Images of a vertical slice of the boule and the location of the sample selected to be the focus of our study are shown in Fig. 1. The elemental composition of samples taken near CG63.AB.AD.1 is shown in Table 1 (CG63), along with data showing the elemental compositions of two sister CG63 samples from this growth. Samples CG63 was taken near B at the shoulder, $\mathrm{F}$ in the middle and $\mathrm{J}$ at the heel or last to freeze section of the ingot. Relative to the other two sister samples, the CG63.AB.AD.1.F3 (taken from the vertical middle of the boule) contained a higher level of $\mathrm{C}, \mathrm{Ca}$ and $\mathrm{O}$. A photo of unpolarized IR light was used to examine for cracks, voids, grain boundaries and others major defects in their volume. Secondary phases of unknown composition were readily viewed in a vertical slice of this material as shown in Fig. 2. Computerized imaging analysis of this CG63.AB.AD.1.F3 material calculated an SP volume \% of 0.00214 and an SP density of $465072 \mathrm{~cm}^{-3}$. According to the computerized imaging analyses, the SP had three primary size distributions and an average diameter of $2.4 \mu \mathrm{m}$ (data not shown). Additionally, the dominant shape of these features was spherical. I-V curve measurements revealed that the material has a high resistivity (Fig. 3a 
and $\mathbf{b}$ ) of $\rho v=5.85 \times 10^{9} \Omega \mathrm{cm}$. The electron mobility behavior (mu tau $)_{\mathrm{e}}$ of the annealed CG63.AB.AD.1.F3 sample is shown in Fig. 4. The detector performance of this crystal was evaluated using a ${ }^{57}$ Co gamma radiation source as shown in Fig. 5. The Pulser FWHM values for the annealed sample of CG63.AB.AD.1.F3 was 16.1\%.

Scanning electron microscopy studies that were performed at low magnification with wafer CG63.AB.AD.1.F3 revealed very few large defects on a smooth surface (as shown in Fig. 6a-c). Some dislocations could be observed on one side of the sample as shown in Fig. 6b. Higher resolution SEM studies with wafer CG63.AB.AD.1.F3 revealed the presence of dark near surface features (in Fig. 7a) that were rich in C and O. These dark features occasionally had embedded light-colored SP of roughly $5 \mu \mathrm{m}$ or less in diameter (as shown in Fig. 7a). These SP had elemental compositions of different elemental abundance based on EDX analyses (as shown in Fig. 7bd). One TEM thin section of one of the light-colored SP that was rich in $\mathrm{C}, \mathrm{Ca}$ and $\mathrm{O}$ was made using the FIB technique. $^{12}$ A high-resolution TEM and a HAADF image of this section is shown in Fig. 8a and b. TEM-based HAADF energy dispersive X-ray spectrometry (EDX) analyses (Fig. 9) were used to determine the elemental composition of the SP within the thin section. EDX analyses revealed considerable elemental composition heterogeneity as shown in Fig. 9. Figure 9 also reveals a HAADF image of a portion of the sample that was shown in Fig. 8. The center top portion of Fig. 9 contains an $\mathrm{SP}$ that is rich in $\mathrm{Ca}, \mathrm{C}$ and $\mathrm{O}$ and has trace $\mathrm{S}$ and $\mathrm{Si}$ material. Finally, a low resolution TEM image of the bulk CZT material within thin section is shown in Fig. 10. Selective area electron diffraction (SAED) was used to determine the crystallinity of the bulk CZT in the sample and the single crystal material had an a parameter of $0.643 \mathrm{~nm}$.

\section{CONCLUSION}

This material was of high resistivity and it had a good detector performance the presence of $\mathrm{Ca}, \mathrm{C}$ and O-rich SP did not have a substantial negative influence on the detector performance in our study. It is possible that we were unable to locate all of the SP types/morphologies that were present in this sample using our approach. The SP in sample CG63.AB.AD.1.F3 were probably formed during growth because they served as reservoirs for trapping elemental impurities within the host single crystal matrix. Whether these formed during crystal growth or cool-down could not be determined with the information presented in this paper. This presentation contributes new information about variety in then elemental composition and makeup of SP in CZT gamma radiation spectrometers.

\section{ACKNOWLEDGMENTS}


This work was supported by the US DOE - National Nuclear Security Administration, through the Office of Nonproliferation and Verification Research and Development - NA-22 through DE-FG52-08NA28769.

\section{REFERENCES}

1. J.R. Heffelfinger, D.L. Medlin, and R.B. James. MRS Symp. Ser. 487, 33 (1998).

2. M. Schieber, T.E. Schlesinger, R.B. James, H. Hermon, H. Yoon, and M. Goorsky. J. Crystal Growth 237-239, 2082 (2002).

3. C. Szeles, and M.C. Driver. SPIE Proc. 3446, 1 (1998).

4. C. Szeles, S.E. Cameron, J-O. Ndap, and W.C. Chalmers. IEEE Trans. Nucl. Sci. 49, 2535 (2002).

5. J. Shen, D. K. Aidun, L. Regel, and W.R. Wilcox. J. Crystal Growth 132, 250 (1993).

6. G.A. Carini, A.E. Bolotnikov, G.S. Camarda, G.W. Wright, L. Li, and R.B. James. Appl. Phys. Lett. 88, 143515 (2006).

7. A.E. Bolotnikov, G.S. Camarda, G.A. Carini, Y. Cui, L. Li, and R.B. James, Nucl. Instrum. Meth. A571, 687 (2007).

8. C. Szeles, W.C. Chalmers, S.C. Cameron, J-O. Ndap, M. Bliss, and K.G. Lynn. SPIE Proc. 4507, 57 (2001).

9. M.C. Duff, K.G. Lynn, K. Jones, Z.R. Dai, J.P. Bradley, and N. Teslich, SPIE Proc. 7449, 74490N (2009).

10. P. Rudolph, M. Neubert, and M. Mühlberg. J. Crystal Growth 128, 582 (1993).

11. P. Rudolph, A. Engel, I. Schentke, and A. Grochochi. J. Crystal Growth 147, 297 (1995).

12. M.C. Duff, D.B. Hunter, A. Burger, M. Groza, V. Buliga, J.P. Bradley, G. Graham, Z. Dai, N. Teslich, D.R. Black, and A. Lanzirotti, J. Mat. Res. 24, 1361 (2009).

13. L. Li, F. Lu, K. Shah, M. Squillante, L. Cirinano, W. Yao, R.W. Olson, P. Luke, Y. Nemirovsky, A. Burger, G. Wright, and R.B. James. Nucl. Sci. Symp. Conf. Rec. IEEE 4, 2396 (2001).

14. H. Chen, S. A. Awadalla, J. Mackenzie, R. Redden, G. Bindley, A. E. Bolotnikov, G. S. Camarda, G. Carini, and R. B. James. IEEE Trans. Nucl. Sci., 54, 811 (2007).

15. H. Chen, S.A. Awadalla, K. Iniewski, P.H. Lu, F. Harris, J. Mackenzie, T. Hasanen, W. Chen, R. Redden, G.

Bindley, I. Kuvvetli, C. Budtz-Jørgensen, P. Luke, M. Amman, J.S. Lee, A.E. Bolotnikov, G.S. Camarda, Y. Cui, A. Hossain, and R.B. James. J. Appl. Phys. 103, 014903 (2008).

16. M. Ohmari, Y. Iwase, and R. Ohno. Mat. Sci. Eng., B16, 283 (1993).

17. R. Triboulet. Prog. Cryst. Growth Char. Matter, 128, 85 (1994). 
Table 1. Glow discharge mass spectrometric report for CG63 in ppb (atomic) or as noted. Measurements performed by A. Mykytiuk and B. Methven of the Institute for National Measurement Standards, Canada.

\begin{tabular}{|c|c|c|c|}
\hline Element & Tip & Middle & Heel \\
\hline $\mathrm{Li}$ & $<2$ & $<2$ & $<2$ \\
\hline $\mathrm{Be}$ & $<2$ & $<2$ & $<2$ \\
\hline B & $<4$ & $<4$ & $<5$ \\
\hline $\mathrm{C}$ & 20 & 100 & 30 \\
\hline $\mathrm{N}$ & 20 & 20 & 4 \\
\hline $\mathrm{O}$ & 30 & 70 & 50 \\
\hline $\mathrm{F}$ & $<8$ & $<8$ & $<6$ \\
\hline $\mathrm{Na}$ & $<3$ & 14 & 96 \\
\hline $\mathrm{Mg}$ & 21 & 22 & 14 \\
\hline $\mathrm{Al}$ & 410 & 380 & 640 \\
\hline $\mathrm{Si}$ & 3 & $<2$ & 8 \\
\hline $\mathrm{P}$ & $<2$ & $<2$ & $<2$ \\
\hline S & $<95$ & $<60$ & $<60$ \\
\hline $\mathrm{Cl}$ & 7 & $<5$ & 15 \\
\hline K & $<45$ & $<85$ & $<40$ \\
\hline $\mathrm{Ca}$ & $<15$ & $<20$ & $<20$ \\
\hline $\mathrm{Sc}$ & $<0.5$ & $<0.5$ & $<0.6$ \\
\hline $\mathrm{Ti}$ & $<0.4$ & $<0.4$ & 1 \\
\hline V & $<0.3$ & $<0.3$ & $<0.3$ \\
\hline $\mathrm{Cr}$ & $<3$ & $<3$ & 16 \\
\hline $\mathrm{Mn}$ & $<10$ & $<10$ & $<10$ \\
\hline $\mathrm{Fe}$ & $<5$ & $<5$ & 54 \\
\hline Co & $<0.5$ & $<0.6$ & $<0.7$ \\
\hline $\mathrm{Ni}$ & $<3$ & $<3$ & 12 \\
\hline $\mathrm{Cu}$ & $<15$ & 32 & 56 \\
\hline $\mathrm{Zn}$ & $(4.1 \%)$ & $(4.4 \%)$ & $(3.3 \%)$ \\
\hline $\mathrm{Ga}$ & $<3$ & $<3$ & $<3$ \\
\hline $\mathrm{Ge}$ & $<50$ & $<20$ & $<50$ \\
\hline As & $<25$ & $<25$ & $<45$ \\
\hline $\mathrm{Se}$ & $<15$ & $<20$ & $<10$ \\
\hline $\mathrm{Rb}$ & $<0.3$ & $<0.4$ & $<0.4$ \\
\hline $\mathrm{Sr}$ & $<0.2$ & $<0.2$ & $<0.2$ \\
\hline $\mathrm{Y}$ & $<0.2$ & $<0.2$ & $<0.2$ \\
\hline $\mathrm{Zr}$ & $<0.4$ & $<0.4$ & $<0.6$ \\
\hline $\mathrm{Nb}$ & $<0.8$ & $<0.8$ & $<2$ \\
\hline Mo & $<2$ & $<2$ & $<2$ \\
\hline $\mathrm{Ru}$ & $<4$ & $<5$ & $<6$ \\
\hline $\mathrm{Rh}$ & $<65$ & $<75$ & $<50$ \\
\hline
\end{tabular}

\begin{tabular}{|c|c|c|c|}
\hline Element & Tip & Middle & Heel \\
\hline $\mathrm{Pd}$ & $<20$ & $<25$ & $<35$ \\
\hline $\mathrm{Ag}$ & $<30$ & $<35$ & $<55$ \\
\hline $\mathrm{Cd}$ & Matrix & Matrix & Matrix \\
\hline In & 1200 & 1600 & 5100 \\
\hline $\mathrm{Sn}$ & $<15$ & $<15$ & $<20$ \\
\hline $\mathrm{Sb}$ & $<25$ & $<30$ & $<35$ \\
\hline $\mathrm{Te}$ & Matrix & Matrix & Matrix \\
\hline I & $<890$ & $<360$ & $<400$ \\
\hline Cs & $<2$ & $<2$ & $<3$ \\
\hline $\mathrm{Ba}$ & $<3$ & $<2$ & $<4$ \\
\hline $\mathrm{La}$ & $<0.1$ & $<0.2$ & $<0.2$ \\
\hline $\mathrm{Ce}$ & $<0.2$ & $<0.5$ & $<0.3$ \\
\hline $\operatorname{Pr}$ & $<0.2$ & $<0.4$ & $<0.3$ \\
\hline $\mathrm{Nd}$ & $<1$ & $<1$ & $<1$ \\
\hline $\mathrm{Sm}$ & $<40$ & $<30$ & $<30$ \\
\hline $\mathrm{Eu}$ & $<1200$ & $<720$ & $<960$ \\
\hline $\mathrm{Gd}$ & $<3$ & $<7$ & $<15$ \\
\hline $\mathrm{Tb}$ & $<0.8$ & $<0.7$ & $<1$ \\
\hline Но & $<7$ & $<6$ & $<8$ \\
\hline Er & $<4$ & $<5$ & 12 \\
\hline $\mathrm{Tm}$ & $<0.9$ & $<1$ & $<1$ \\
\hline $\mathrm{Yb}$ & $<10$ & $<8$ & $<10$ \\
\hline $\mathrm{Lu}$ & $<6$ & $<6$ & $<8$ \\
\hline $\mathrm{Hf}$ & $<12$ & $<11$ & $<8$ \\
\hline W & $<3$ & $<3$ & $<4$ \\
\hline $\mathrm{Re}$ & $<1$ & $<1$ & $<0.8$ \\
\hline Os & $<7$ & $<7$ & $<8$ \\
\hline $\mathrm{Ir}$ & $<3$ & $<2$ & $<3$ \\
\hline $\mathrm{Pt}$ & $<3$ & $<3$ & $<4$ \\
\hline $\mathrm{Au}$ & $<5$ & $<5$ & $<5$ \\
\hline $\mathrm{Hg}$ & $<3$ & $<3$ & $<4$ \\
\hline $\mathrm{Tl}$ & $<0.9$ & $<0.9$ & $<1$ \\
\hline $\mathrm{Pb}$ & $<1$ & $<0.9$ & $<1$ \\
\hline $\mathrm{Bi}$ & $<0.6$ & $<0.6$ & $<0.7$ \\
\hline Th & $<0.6$ & $<0.7$ & $<1$ \\
\hline $\mathrm{U}$ & $<1$ & $<1$ & $<2$ \\
\hline
\end{tabular}




\section{CG63.AB.AD.1 slice \\ Cut into $10 \mathrm{~mm} \times 10 \mathrm{~mm}$ samples}

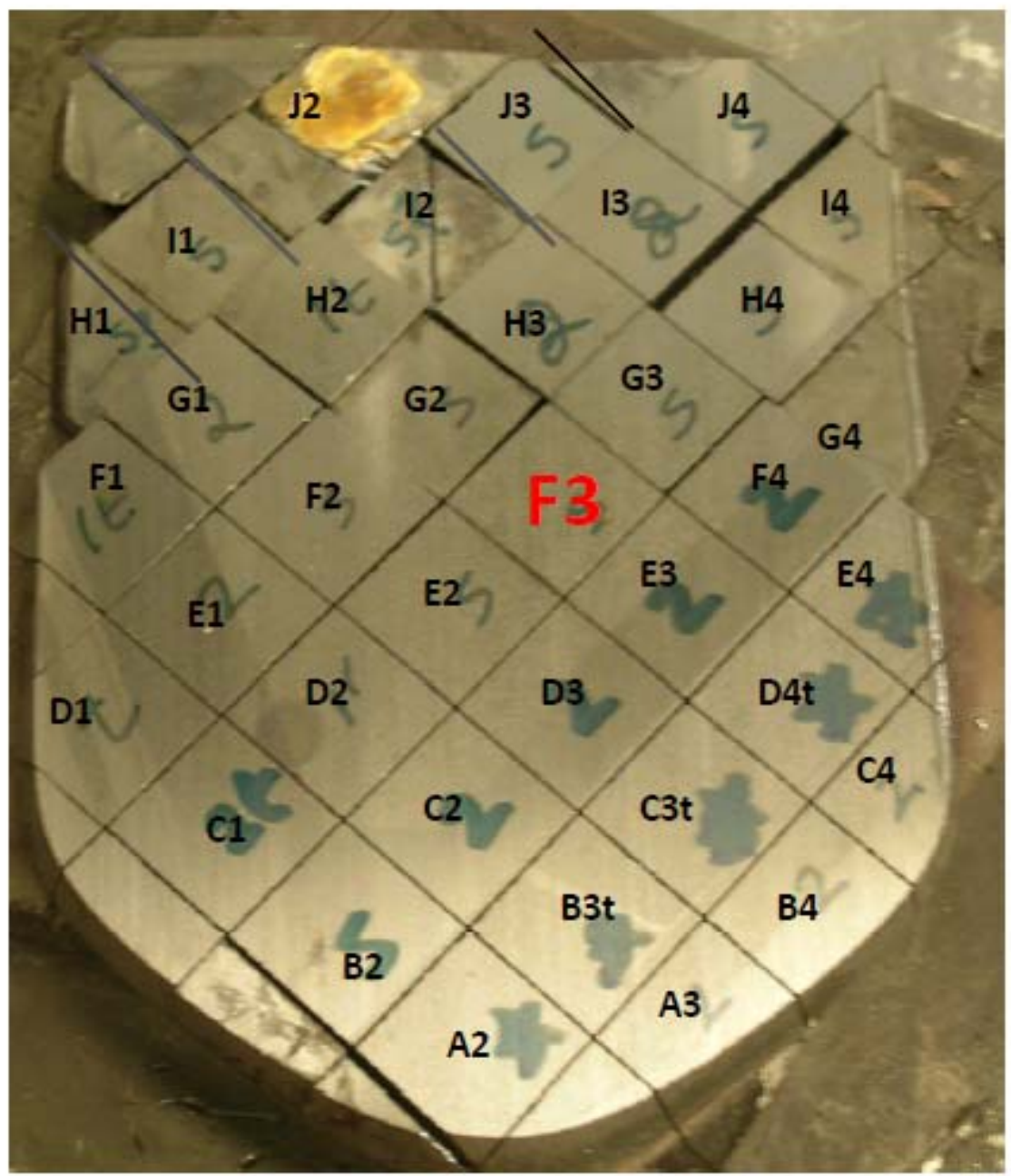

Fig. 1. Photograph of CG63.AB.AD.1 slice showing location of wafer CG63.AB.AD.1.F3 (at center) in addition other digitally-annotated neighboring wafers from this slice. 


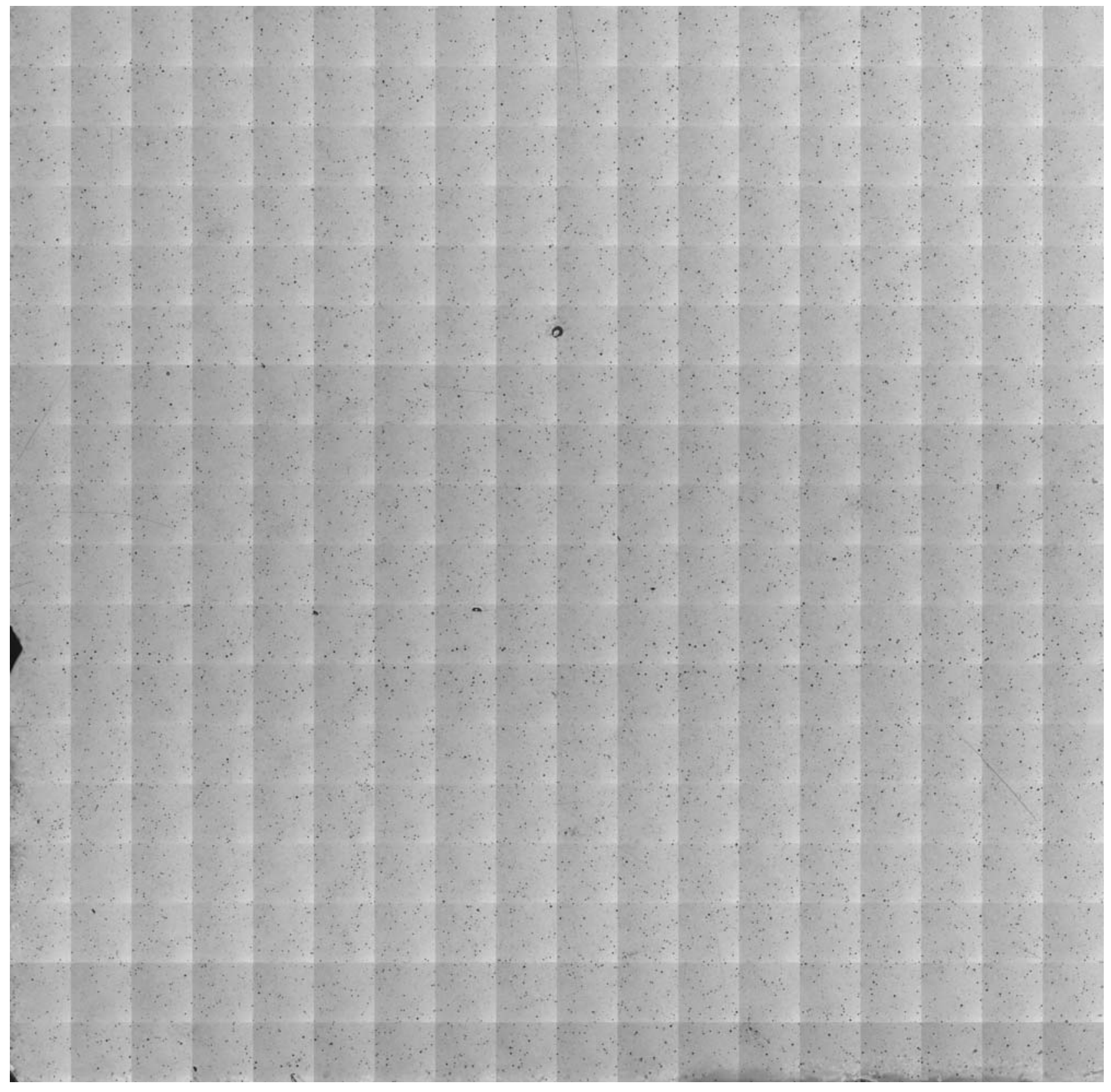

Fig. 2. Transmission IR imaging data for CG63.AB.AD.1.F3. 


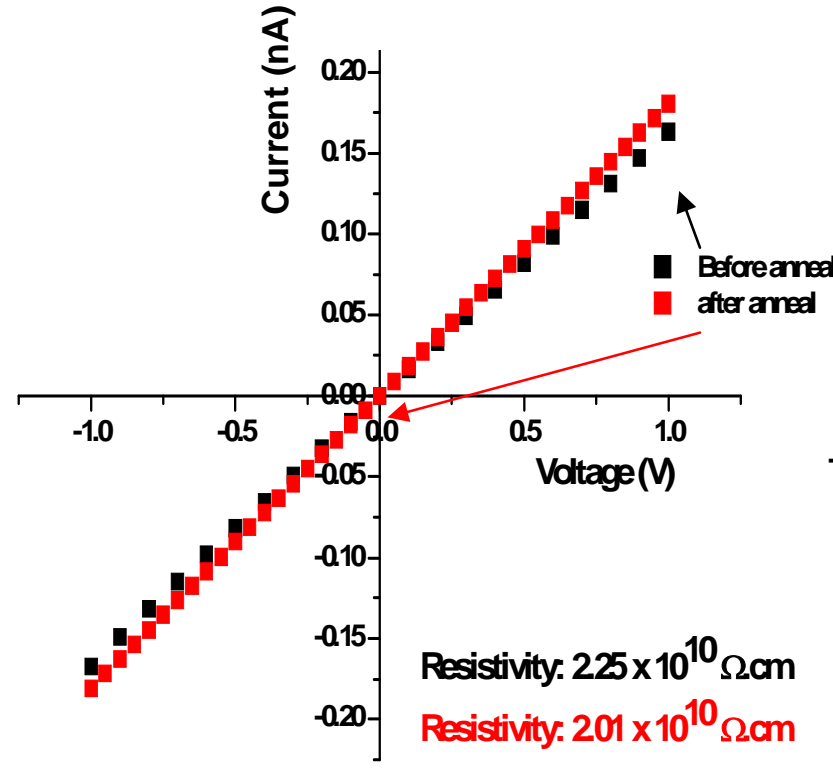

a)

Fig. 3. Bulk resistivity data for CG63.AB.AD.1.F3 (before and after anneal in oxygen for 8 hrs at $75^{\circ} \mathrm{C}$ ) for $\left.\mathbf{a}\right)-1.0 \mathrm{~V}$ to $+1.0 \mathrm{~V}$ and for $\mathbf{b}$ ) $-25 \mathrm{~V}$ to $25 \mathrm{~V}$ (after anneal) and for $-11 \mathrm{~V}$ to $+11 \mathrm{~V}$ before anneal. 


\section{CG63.AB.AD.1.F3: Co-57 spectrum}

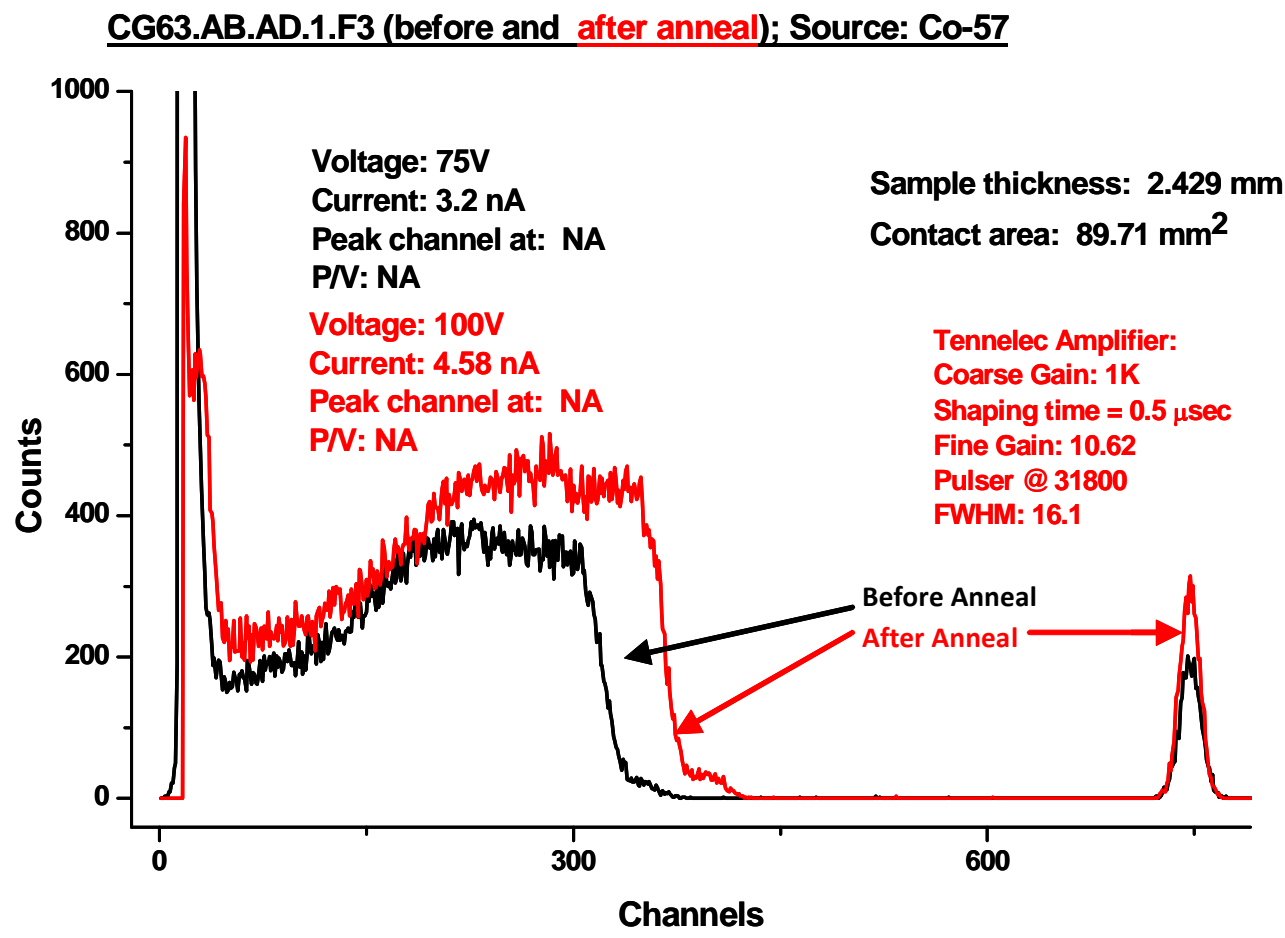

Fig. 4. Gamma radiation spectrometer data for CG63.AB.AD.1.F3 before and after anneal in oxygen for $8 \mathrm{hrs}$ at $75^{\circ} \mathrm{C}$. 


\section{CG63.AB.AD.1.F3.after anneal: $\mu \tau$ with Cs-137 source}

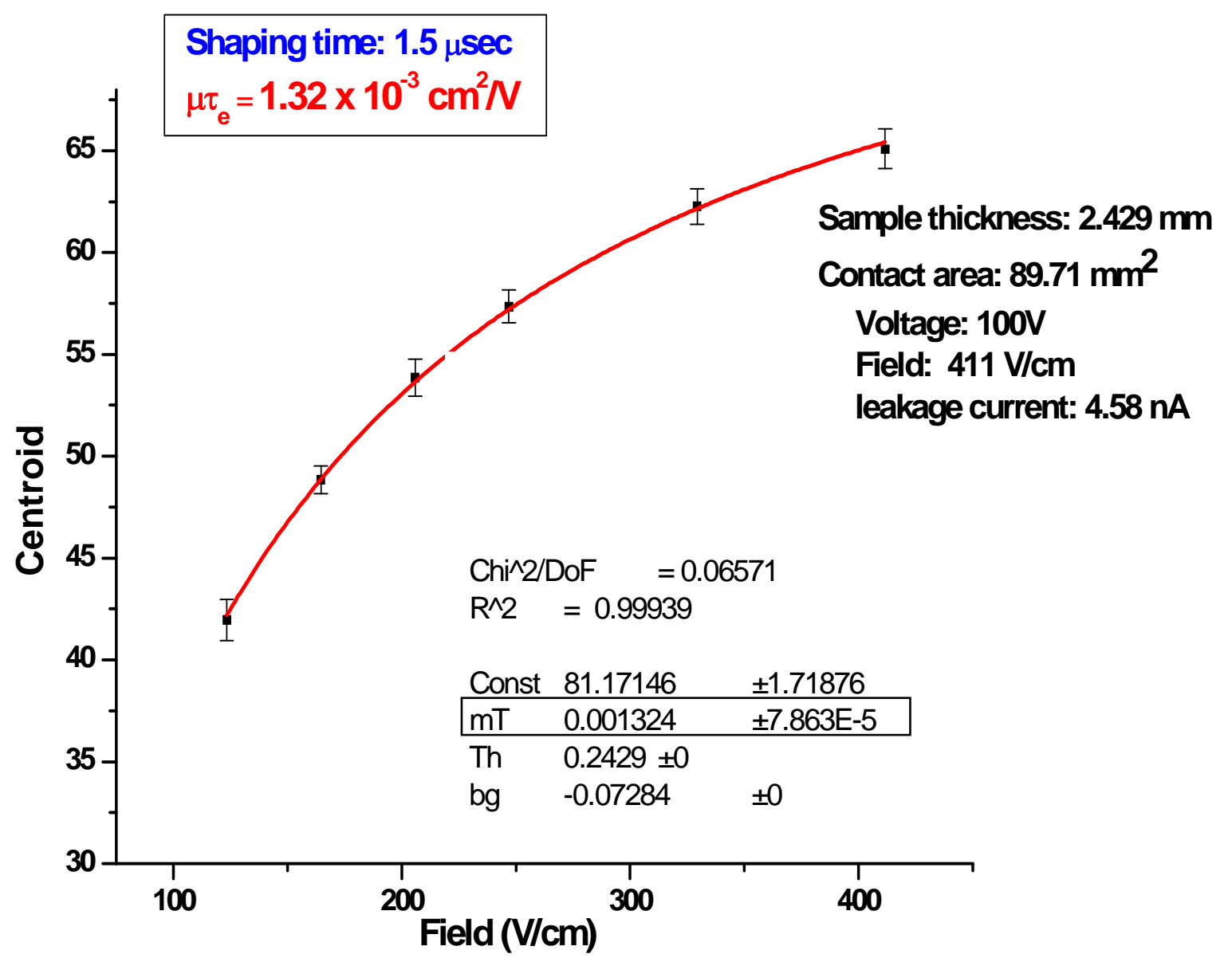

Fig. 5. Electron mobility data for CG63.AB.AD.1.F3 after anneal in oxygen for $8 \mathrm{hrs}$ at $75^{\circ} \mathrm{C}$ showing a mu tau of $1.32 \times 10^{-3} \mathrm{~V} \mathrm{~cm}^{-1}$. The energy of the ${ }^{137} \mathrm{Cs}$ emission used was $30 \mathrm{keV}$. 

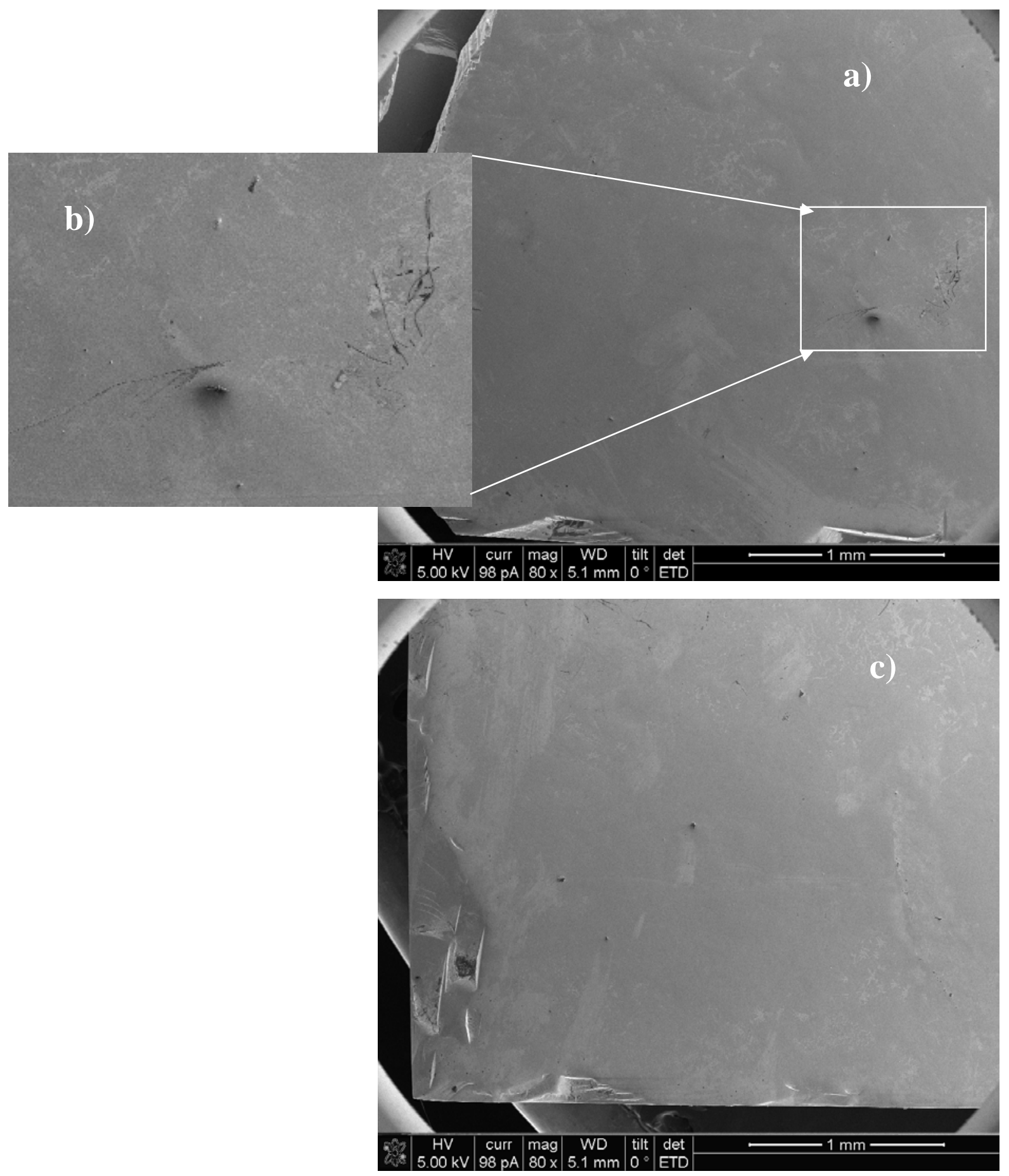

Fig. 6. Low magnification SEM images of both sides of CG63.AB.AD.1.F3 showing a fairly uniform surface as in images: a), b) (which is an inset of a) and c). Image b) reveals several features that appear to be dislocations on or near the surface. 


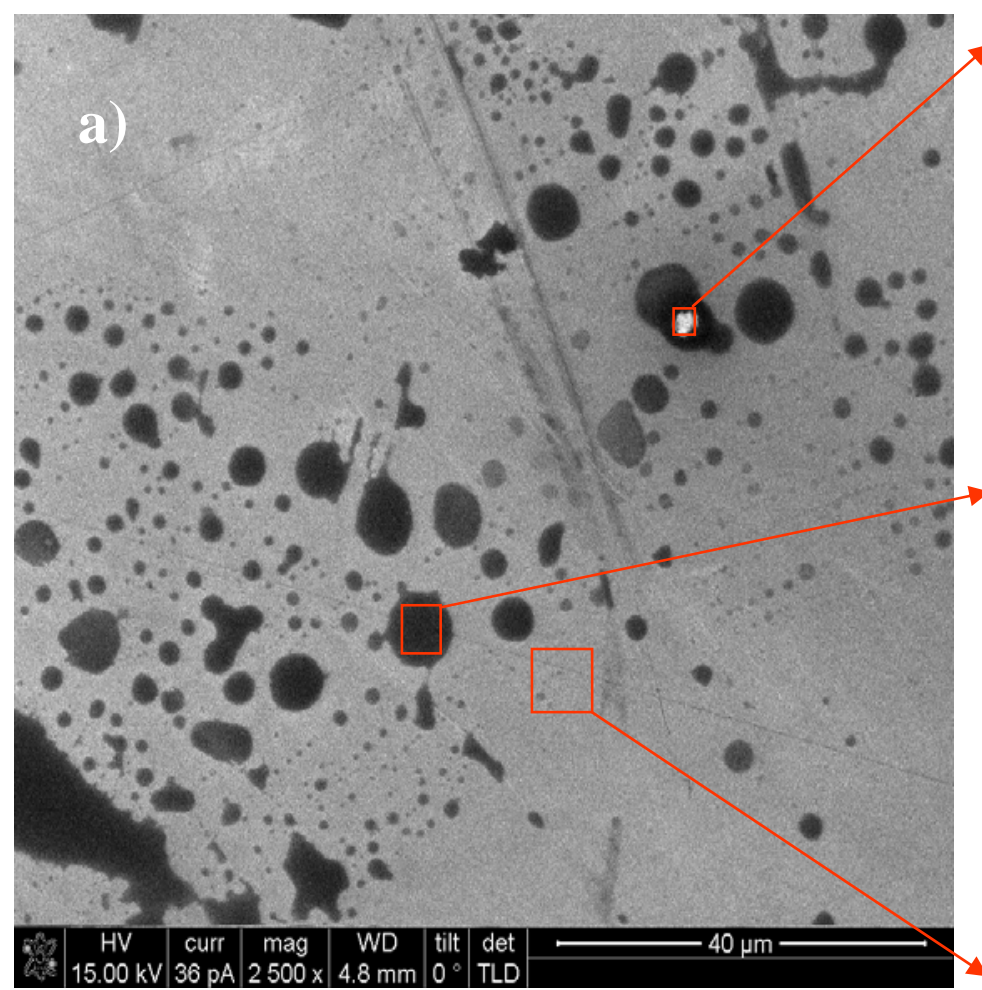

Fig. 7. Micrometer-scale dark-contrast areas were observed in an SEM image as shown in a). EDX analysis (spectra shown in b-d) indicates one SP found in the dark-contrast area contained elemental C, O and $\mathrm{Ca}$ (see EDX spectra in $\mathbf{b}$ ) and that the dark areas contain higher $\mathrm{C}$ and $\mathrm{O}$ (EDX spectra shown in c) than that found in the light-contrast background area (EDX spectra shown in $\mathbf{d}$ ).
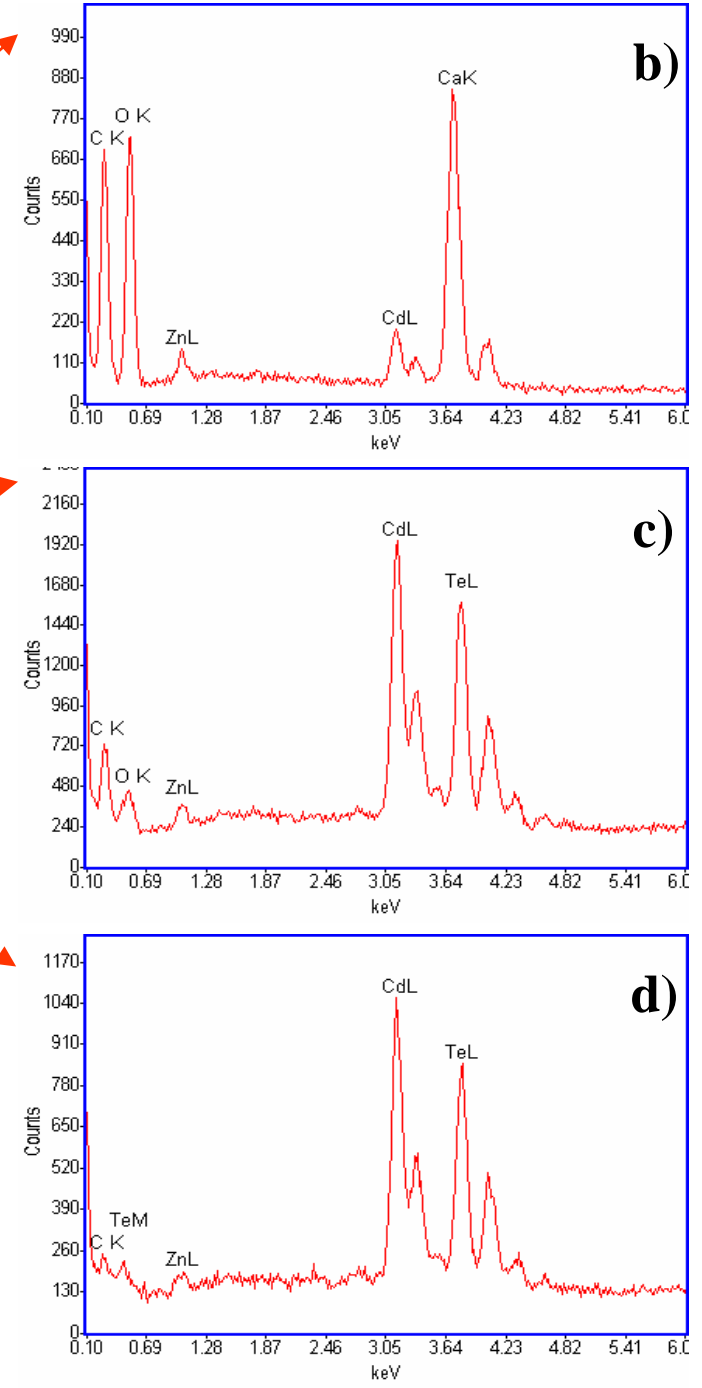


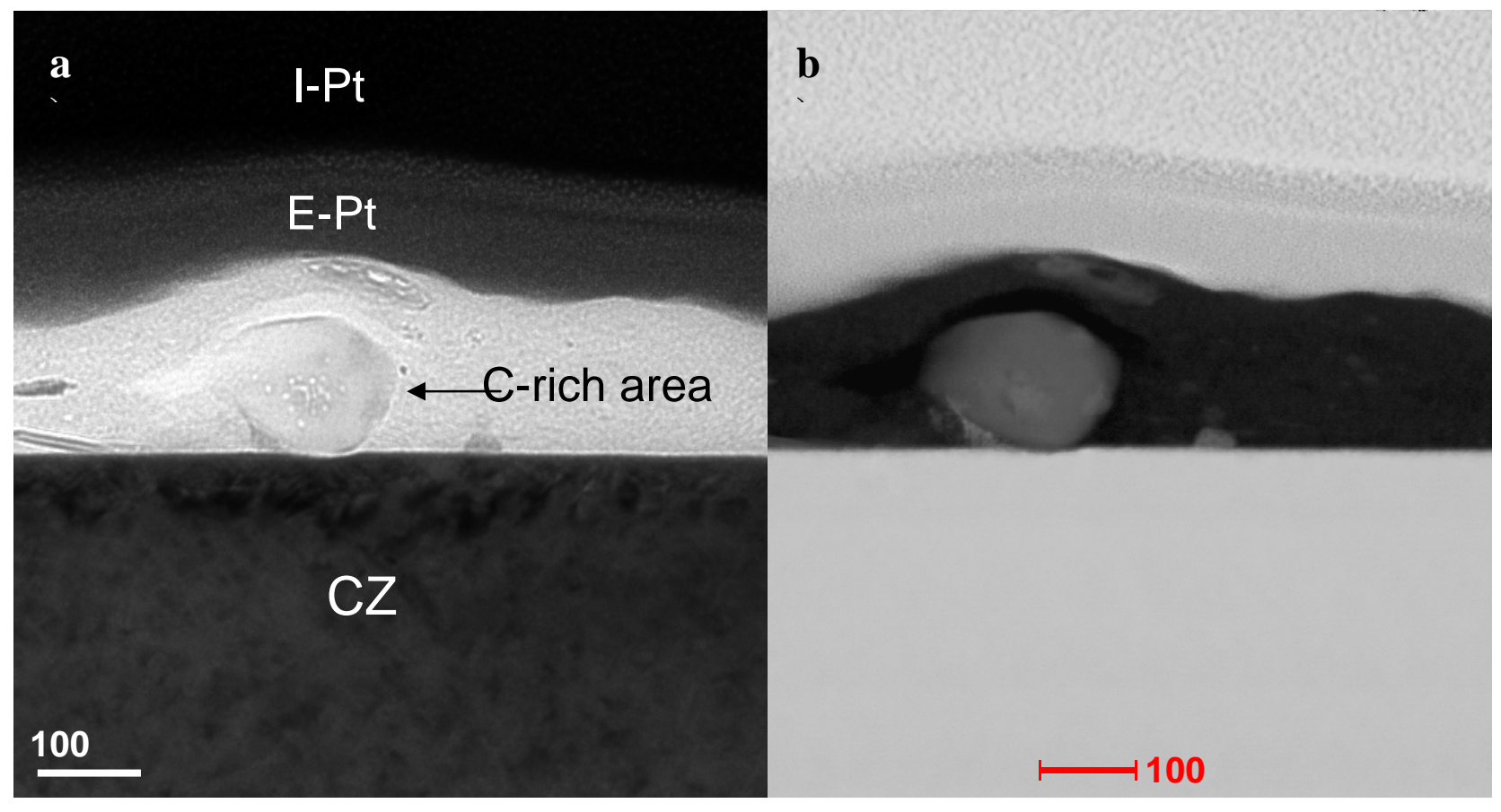

Fig. 8. Bright-field TEM image in a) and corresponding HAADF STEM image in b), showing a particle sitting near the CZT surface. EDX analysis indicates the particle contains $\mathrm{O}, \mathrm{C}$ and $\mathrm{Ca}$. 

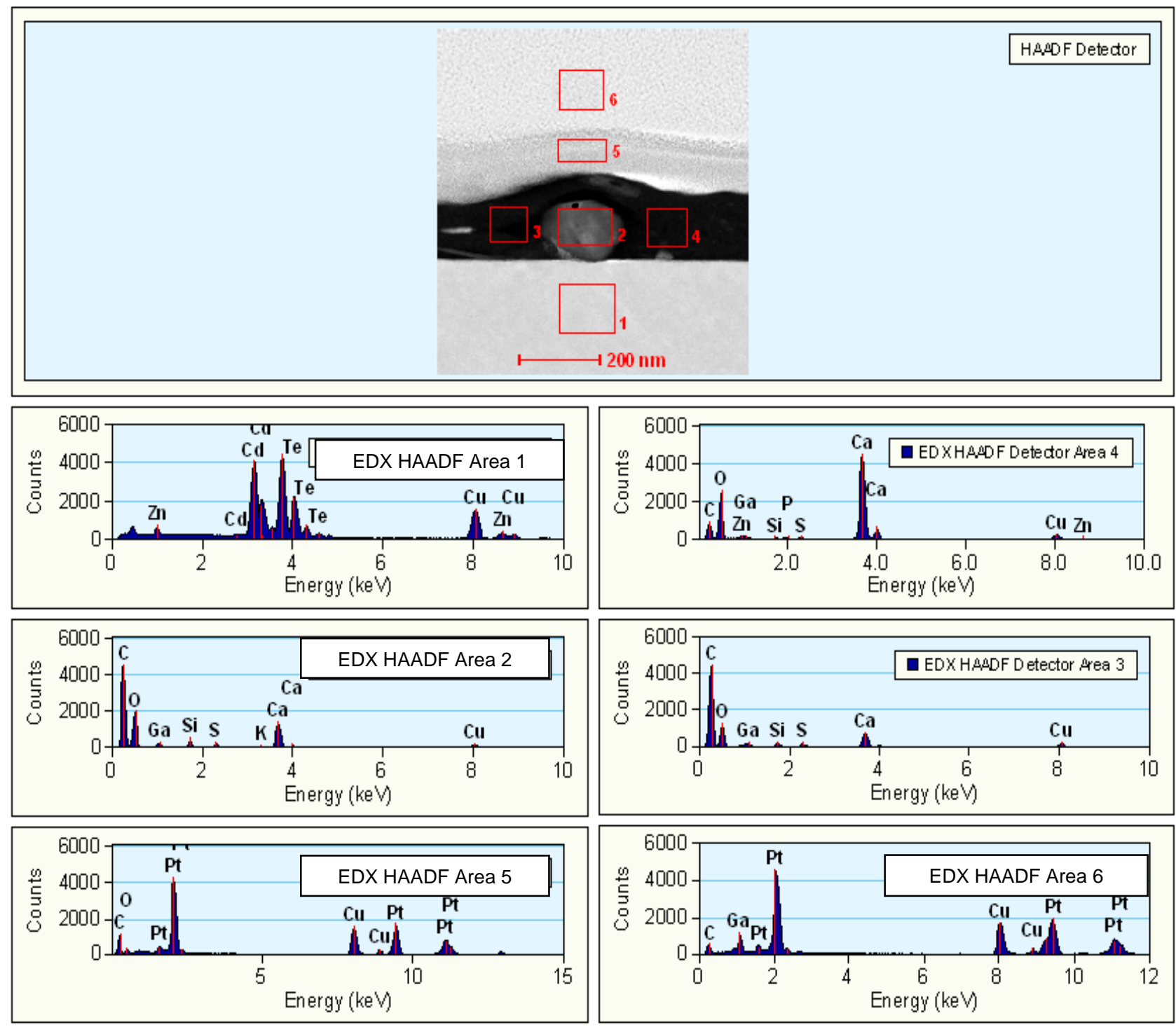

Fig. 9. HAADF STEM image (top) showing EDX spectra for six (6) areas on the sampleas noted in the top image. Area 2 represents the $\mathrm{C}, \mathrm{Ca}$ and $\mathrm{O}$-rich particle, which has trace levels of S and Si. Trace S and Si were found in the areas on either side of Area 2. Area 6 corresponds to the Pt material that is place on the thin section surface for stability during handling. 


\section{Sample: CG63.AB.AD.1.F3}

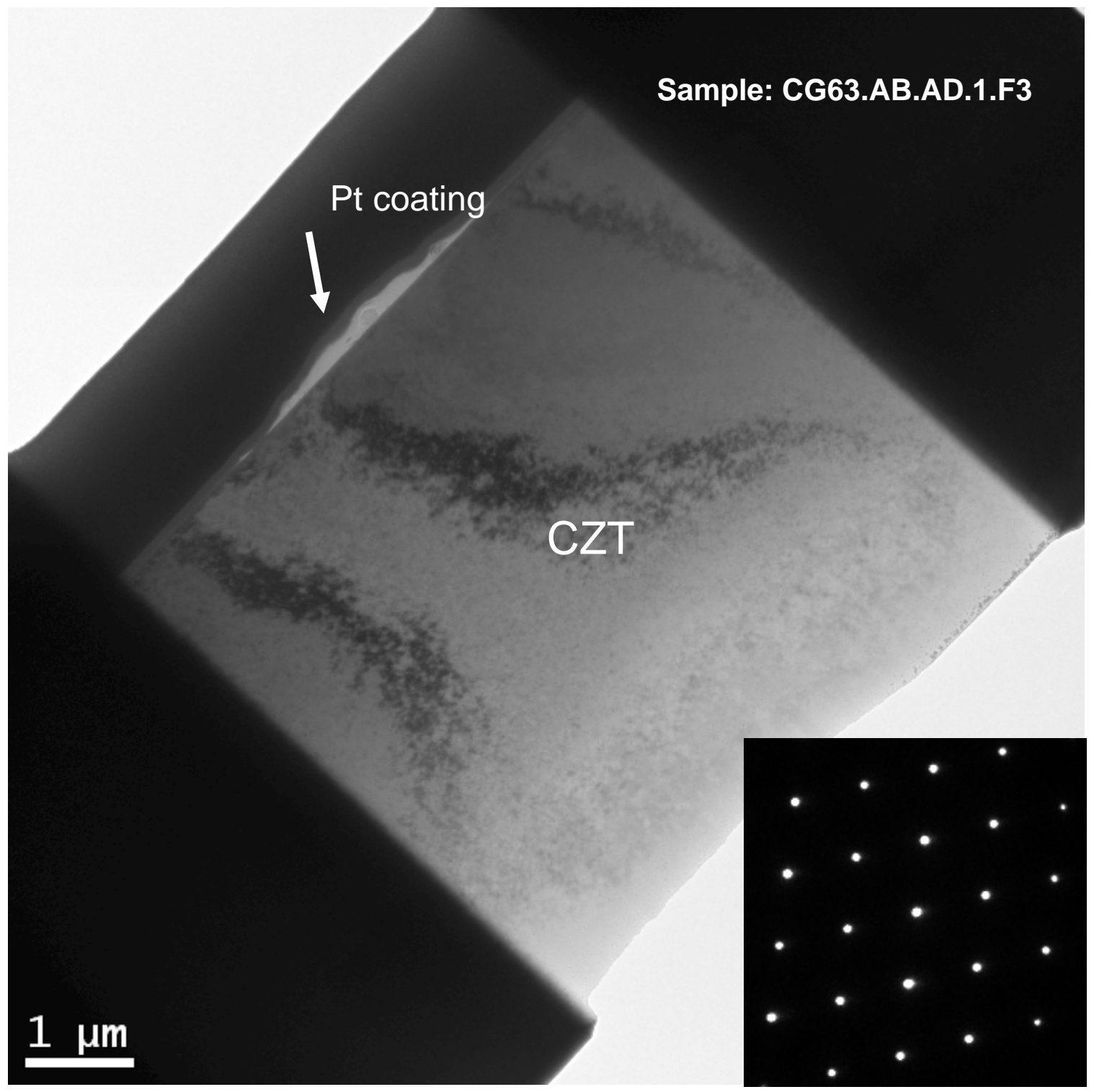

Fig. 10. A low magnification bright-field TEM image. The right corner inset shows the select area electron diffraction (SAED) pattern ([110] zone axis) for the CZT, which indicates it is a single crystal with a lattice parameter of $\mathrm{a}=0.643 \mathrm{~nm}$. EDX analysis (data not shown) determined its composition is $\mathrm{Cd}_{43.4} \mathrm{Zn}_{5.3} \mathrm{Te}_{51.3}$. 